\title{
ERRATUM
}

\section{Erratum to: Failure Analysis and Finite Element Simulation of Above Ground Oil-Gas Pipeline Impacted by Rockfall}

\author{
J. Zhang $\cdot$ Z. Liang $\cdot$ C. J. Han
}

Published online: 29 July 2014

(C) ASM International 2014

Erratum to: J Fail. Anal. and Preven.

\section{DOI 10.1007/s11668-014-9847-x}

Figure 15 is not correct in the original article. The correct figure is as follows:
The online version of the original article can be found under doi:10.1007/s11668-014-9847-x.

\section{J. Zhang $\cdot$ Z. Liang $(\bowtie) \cdot$ C. J. Han}

School of Mechatronic Engineering, Southwest Petroleum

University, Chengdu 610500, Sichuan, China

e-mail: liangz_2242@126.com

\section{J. Zhang}

e-mail: longmenshao@163.com

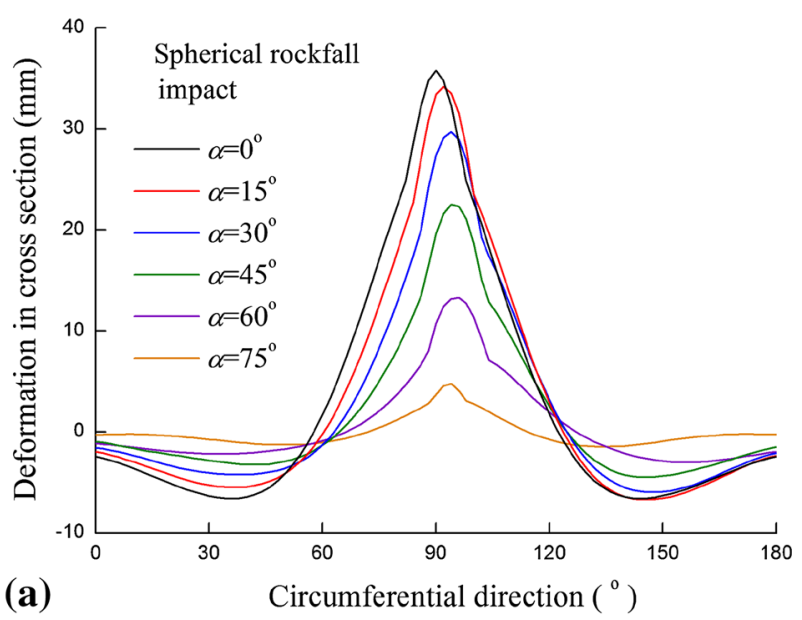

(a)

Circumferential direction $\left({ }^{\circ}\right)$

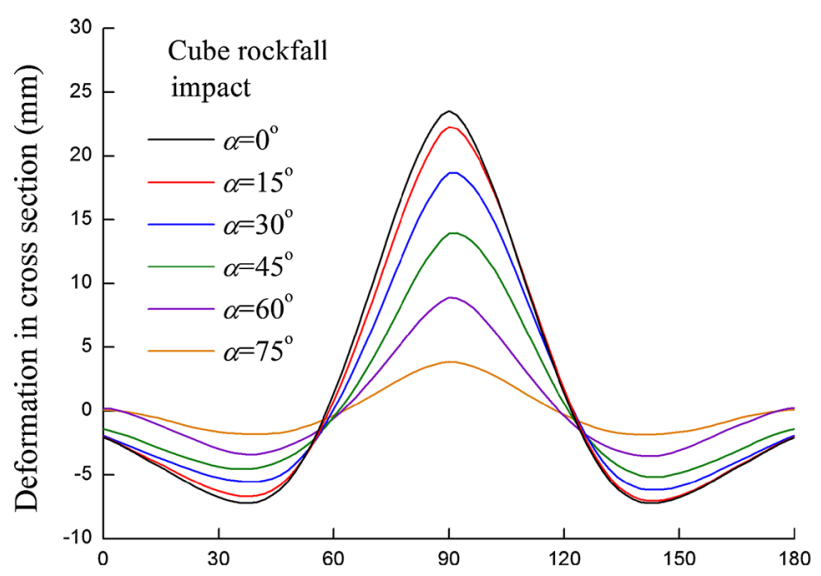

(b)

$$
\text { Circumferential direction }\left({ }^{0}\right)
$$

Fig. 15 Pipeline deformation in cross surface 